\title{
Endoscopic management of acute leak after sleeve gastrectomy: principles and techniques
}

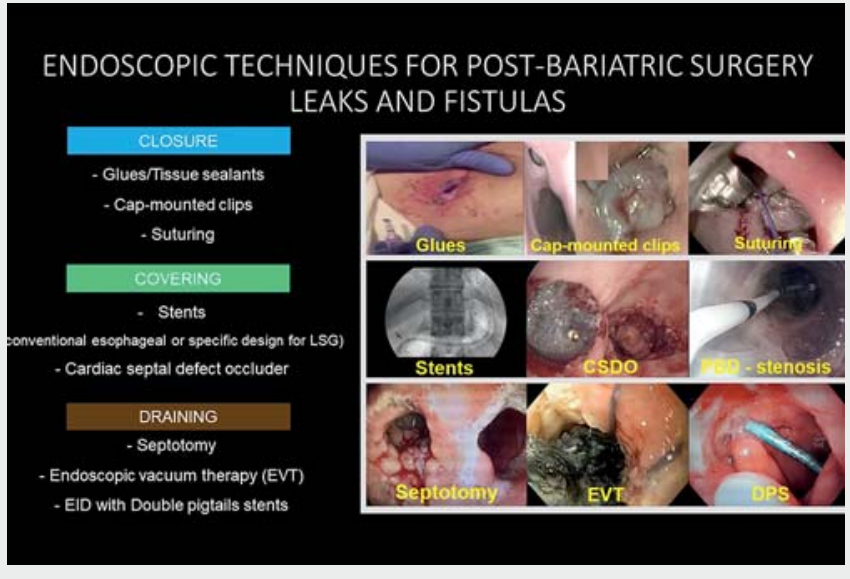

$\checkmark$ Video 1 Endoscopic techniques for post-bariatric surgery leaks and fistulas.
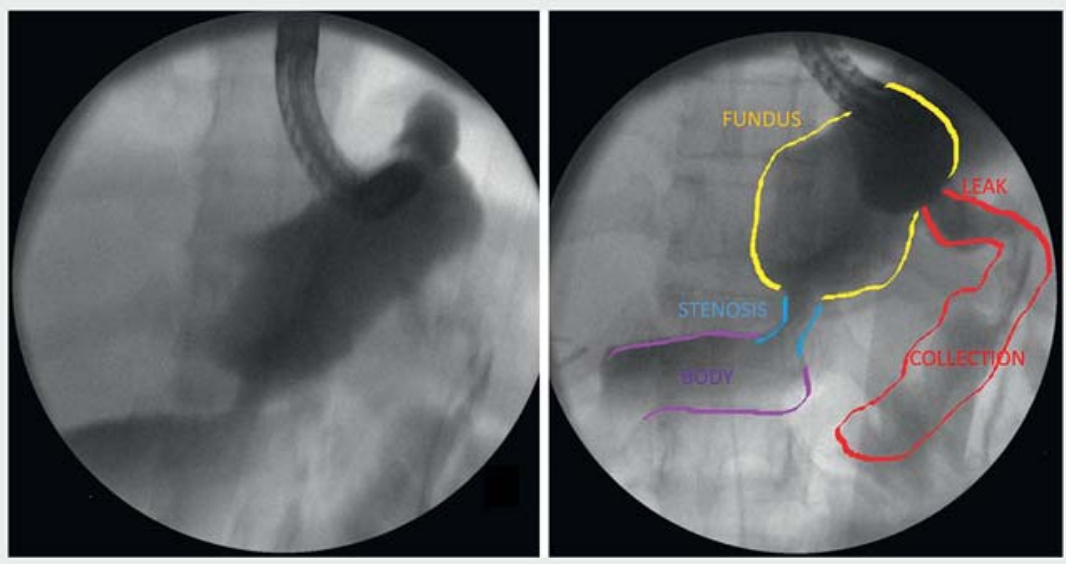

- Fig. 1 Fluoroscopic imaging demonstrating a large perigastric fluid collection from an acute sleeve leak within the residual fundus after laparoscopic sleeve gastrectomy.

Although laparoscopic sleeve gastrectomy (LSG) is the most commonly performed bariatric surgery worldwide, postsleeve leaks may occur in up to $5.3 \%$ of patients [1]. More recently, novel endoscopic draining therapies including endoscopic vacuum therapy, septotomy, and the use of endoluminal double-pigtail stents (DPS) have been deployed [24]. In this video, we describe successful endoscopic internal drainage of a perigastric sleeve leak using DPS ( $>$ Video 1 ). A 35-year-old woman presented to our institution 1 week after LSG with abdominal pain and fever. Initial endoscopy and fluoroscopy revealed an acute post-LSG leak in the residual fundus with purulent drainage and an associated large fluid collection ( $>$ Fig. 1, > Fig. 2). Given these findings, the decision was made to place

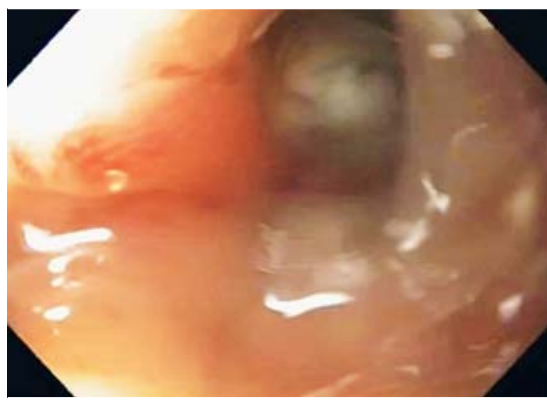

Fig. 2 Endoscopic imaging showing the leak orifice.

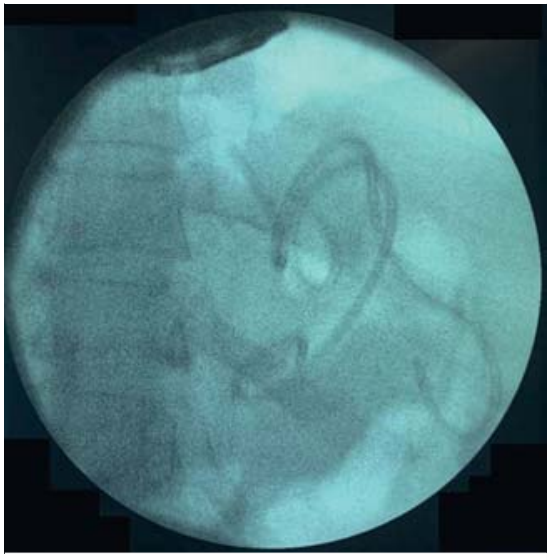

- Fig. 3 Fluoroscopic imaging confirming appropriate positioning of the two double-pigtail plastic stents to achieve successful endoscopic internal drainage.

two DPS $(7 \mathrm{Fr} \times 9 \mathrm{~cm})$ to achieve successful endoscopic internal drainage ( $\triangleright$ Fig.3). The patient was discharged 3 days later without complications receiving a full liquid diet and a course of oral antibiotics. The DPS were removed 1 month after the procedure. At that time, endoscopic and fluoroscopic evaluation demonstrated resolution of the leak and the associated fluid collection ( $\mathbf{F i g . 4}$ ). At the same time, a sleeve stenosis was observed and pneumatic balloon dilation $(30 \mathrm{~mm})$ performed until the radiological "waist" was disrupted ( $\mathbf{F i g} \cdot \mathbf{5})$. After dilation, the endoscope was easily able to traverse the site of the earlier stenosis. 


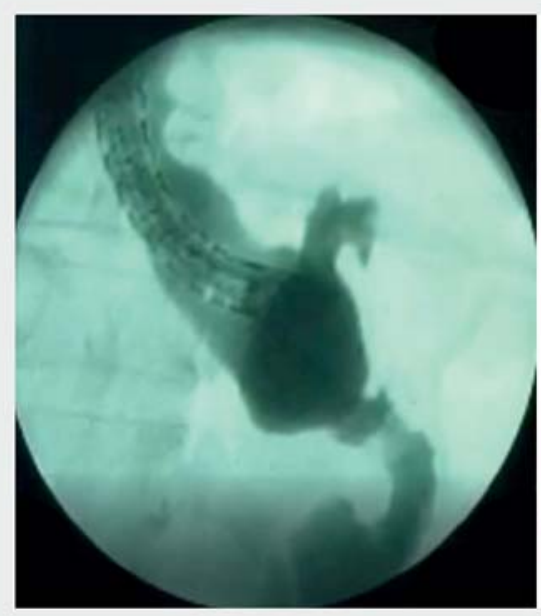

Fig.4 Fluoroscopic imaging after removal of the double-pigtail stents, demonstrating complete resolution of the sleeve leak and associated fluid collection.

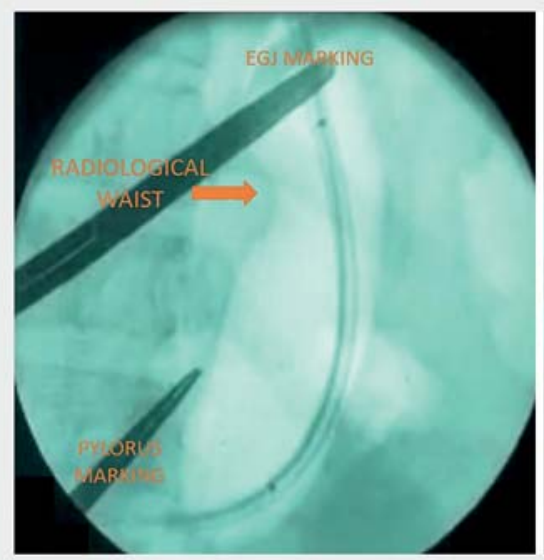

- Fig.5 Pneumatic balloon dilation of the sleeve stenosis showing the disruption of the "radiological waist."

Approximately 2 months later, the patient remained asymptomatic with the diet advanced without any problems.

In summary, endoscopic techniques to treat complications following bariatric surgery are feasible, safe, and effective when the correct approach is selected. In this video, we review principles and techniques of sleeve leaks and describe successful endoscopic management of an acute leak 1 week after LSG. Ultimately, endoscopic internal drainage is a welltolerated option to achieve complete drainage of acute post-LSG leaks and col-
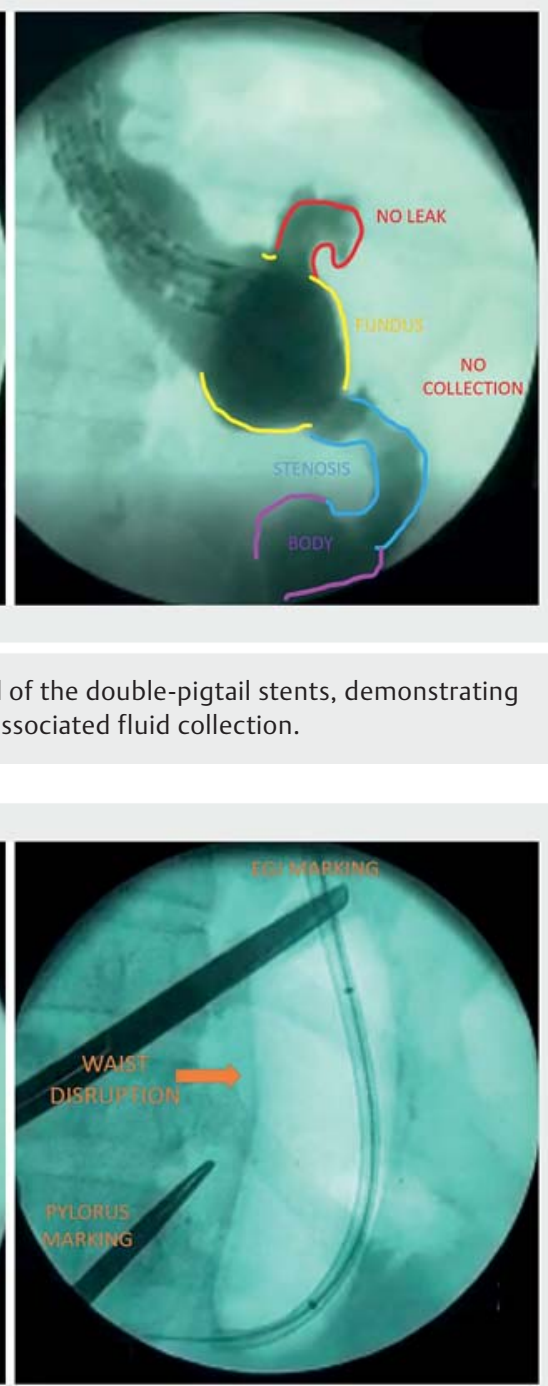

The authors

Diogo Turiani Hourneaux de Moura ${ }^{1} \stackrel{\oplus}{\text { J João }}$ Remí de Freitas Júnior ${ }^{1}{ }^{\oplus}$, Gabriel Mayo Vieira de Souza', Guilherme Henrique Peixoto de

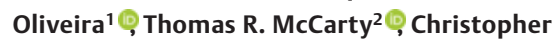
C. Thompson ${ }^{2}$, Eduardo Guimarães Hourneaux de Moura' ${ }^{\odot}$

1 Gastrointestinal Endoscopy Unit, Gastroenterology Department, Hospital das Clínicas da Faculdade de Medicina da Universidade de São Paulo, Brazil

2 Gastroenterology, Hepatology and Endoscopy Division - Harvard Medical School, Brigham and Women's Hospital, Boston, Massachusetts, USA

\section{Corresponding author}

\section{Guilherme Henrique Peixoto de Oliveira, MD \\ Av. Dr Enéas de Carvalho Aguiar, 225, \\ $6^{\circ}$ andar, bloco 3, Cerqueira César, 05403-010 - São Paulo, SP, Brazil guilherme.hpoliveira@hc.fm.usp.br}

\section{References}

[1] Hamid HKS, Emile SH, Saber AA et al. Customized bariatric stents for sleeve gastrectomy leak: are they superior to conventional esophageal stents? A systematic review and proportion meta-analysis. Surg Endosc 2021; 35: 1025-1038

[2] de Moura DTH, Sachdev AH, Thompson CC. Endoscopic full-thickness defects and closure techniques. Curr Treat Options Gastroenterol 2018; 16: 386-405

[3] Haito-Chavez Y, Kumbhari V, Ngamruengphong $S$ et al. Septotomy: an adjunct endoscopic treatment for post-sleeve gastrectomy fistulas. Gastrointest Endosc 2016; 83: 456-457

[4] Boghossian MB, Funari MP, do Monte Junior ES et al. Endoscopic septotomy for fistula after bariatric surgery. Endoscopy 2021; 6: 569-672

[5] Donatelli G, Dumont JL, Cereatti F et al. Treatment of leaks following sleeve gastrectomy by endoscopic internal drainage (EID). Obes Surg 2015; 25: 1293-1301

\section{Competing interests}

The authors declare that they have no conflict of interest.

\section{Bibliography}

Endoscopy 2022; 54: E327-E328

DOI 10.1055/a-1525-1661

ISSN 0013-726X

published online 9.7.2021

(c) 2021. Thieme. All rights reserved.

Georg Thieme Verlag KG, Rüdigerstraße 14,

70469 Stuttgart, Germany 